\title{
Response to mRNA vaccination for COVID-19 among patients with multiple myeloma
}

Samuel D. Stampfer ${ }^{1}{ }^{1}$, Marissa-Skye Goldwater ${ }^{2}$, Scott Jew ${ }^{2}$, Sean Bujarski ${ }^{2}$, Bernard Regidor ${ }^{3}$, David Daniely ${ }^{2}$, Haiming Chen ${ }^{2}$, Ning $\mathrm{Xu}^{2}$, Mingjie Li ${ }^{2}$, Tracy Green ${ }^{3}$, Eddie Fung ${ }^{3}$, Elias Aquino ${ }^{3}$, Regina Swift ${ }^{3}$, Shahrooz Eshaghian ${ }^{4}$, Kurt Preugschat ${ }^{5}$, Aaron J. Feinstein ${ }^{6,7}$, Tanya M. Spektor ${ }^{8}$ and James R. Berenson (iD ${ }^{2,3,8} \bowtie$

(C) The Author(s), under exclusive licence to Springer Nature Limited 2021

Multiple myeloma (MM) patients are at higher risk for severe COVID-19. Their mRNA vaccination response against SARS-CoV-2 is unknown. Thus, we analyzed responses to mRNA vaccination against COVID-19 among these patients. Using an ELISA-based assay that detects IgG antibodies to SARS-CoV-2 spike protein, we determined serum antibody levels prior to immunization and 12-21 and 14-21 days following the first and second vaccinations, respectively, with mRNA-1273 (Moderna) or BNT162b2 (Pfizer/ BioNTech) among $103 \mathrm{MM}$ patients (96 and 7 with active and smoldering disease, respectively). We stratified patients into clinically relevant responders $(>250 \mathrm{IU} / \mathrm{mL})$, partial responders $(50-250 \mathrm{IU} / \mathrm{mL}$, which was above pre-COVID-19 background), and nonresponders $(<50 \mathrm{lU} / \mathrm{mL})$. Smoldering $\mathrm{MM}$ patients responded better than those with active disease. Only $45 \%$ of active MM patients developed an adequate response, while $22 \%$ had a partial response. Lower spike antibody levels were associated with older age, impaired renal function, low lymphocyte counts, reduced uninvolved immunoglobulin levels, $\geq$ second line of treatment, and among those not in complete remission. Patients who received mRNA-1273 vaccine had higher anti-spike antibody levels than those who were vaccinated with BNT162b2. Thus, most MM patients have impaired responses to mRNA vaccination against COVID19 , and specific clinical and myeloma-related characteristics predict vaccine responsiveness.

Leukemia (2021) 35:3534-3541; https://doi.org/10.1038/s41375-021-01354-7

\section{INTRODUCTION}

COVID-19 has already killed $0.05 \%$ of the world population, with the true tally likely much higher [1]. The elderly and immunocompromised are particularly vulnerable, experiencing much higher rates of mortality [2]. The highly effective mRNA vaccines for COVID-19 (BNT162b2 from Pfizer/BioNTech and mRNA-1273 from Moderna) were made available first to these vulnerable populations to achieve the greatest impact on survival per vaccination in this at-risk population. Multiple myeloma (MM) patients are immunocompromised, often elderly, and more likely to develop more severe COVID-19 complications [3]. Thus, these patients received early vaccination with the hope of providing them protection.

Unfortunately, the same mechanisms that impede MM patients' ability to fend off infections also reduce their capability to generate immunity from vaccination, as demonstrated by their diminished responses to vaccines for multiple respiratory illnesses [4]. They develop more frequent infections, and it is a leading cause of death [5]. Factors known to play a role in their higher risk of infection include impaired renal function, low uninvolved immunoglobulin (lg) levels, diminished T-cell responses, reduced neutrophil and lymphocyte counts, immunosuppressive treatments including frequent use of corticosteroids, and disease status [6-12]. While MM patients were targeted early for COVID-19 vaccination, the efficacy of this intervention is unknown.

The first mRNA vaccines for COVID-19, mRNA-1273 and BNT162b2, consist of mRNA encoding prefusion-stabilized SARSCoV-2 spike ectodomain packaged in a lipid nanoparticle [13, 14]. Reactivity against the spike antigen encompasses the entirety of the vaccine-induced immune response against SARS-CoV- 2 . In larger, unselected populations, phase III trial results for mRNA1273 and BNT162b2 COVID-19 vaccines showed an efficacy of 94-95\% against even mild COVID-19 $[15,16]$, but this may be lower in immunocompromised MM patients.

In this observational trial, we evaluated the antibody responses to the two mRNA vaccines against COVID-19, mRNA-1273 and BNT162b2, of 103 patients with MM compared to age-matched healthy subjects. Serum samples were obtained from all individuals at baseline and following their first and second doses, and we evaluated their antibody responses using an anti-spike IgG

${ }^{1}$ Division of Infectious Diseases, Department of Medicine, Emory University School of Medicine, Atlanta, GA, USA. ${ }^{2}$ Institute for Myeloma and Bone Cancer Research, West

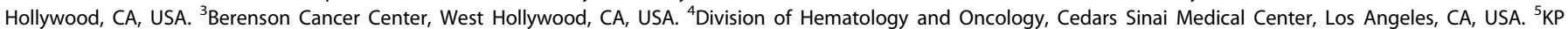

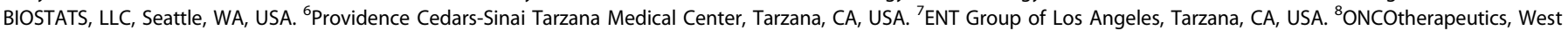
Hollywood, CA, USA. ${ }^{\otimes}$ email: jberenson@berensoncancercenter.org 
assay developed in our laboratory. We also tested serum from healthy subjects obtained prior to COVID-19.

\section{METHODS}

\section{Participants and study design}

Participants in the trial included MM patients from a single clinic specializing in their care, and age-matched healthy controls contemporaneous with the MM study group or prior to the existence of COVID-19. Healthy subjects were not known to be immunocompromised or currently receiving immunosuppressive therapy. Those who could not provide all three sera samples within the designated timepoints were excluded. Vaccination was done outside of the clinic and subjects provided copies of their CDC-issued COVID-19 vaccination cards to confirm dosing dates. Sera from vaccinated individuals were drawn at baseline (0-60 days prior to first vaccine dose) and following their first (12-21 days after dosing with all but 3 obtained at 14-21 days post vaccination) and second (14-21 days following vaccination) doses. Background levels were determined from the clinic's serum bank of healthy subjects drawn between May 9, 2016 and March 15, 2019. Anti-SARS-CoV-2 spike ectodomain antibody levels were quantified in IU/mL based on the WHO International Standard 20/136. Disease-specific markers, creatinine, and blood counts were based on samples drawn at baseline.

\section{Spike antibody quantitative ELISA}

Ninety-six-well plates were coated overnight at $4^{\circ} \mathrm{C}$ with $50 \mu \mathrm{L}$ of SARSCoV-2 purified spike ectodomain at $2 \mu \mathrm{g} / \mathrm{mL}$ (Sino Biological 40589-V08B1, Beijing, China). Coating solution was removed the next morning; plates were blocked with $200 \mu \mathrm{L} \mathrm{3 \%}$ albumin for $1 \mathrm{~h}$ at room temperature (RT). Blocking solution was removed and $50 \mu \mathrm{L}$ patient sera (serially diluted in PBST to 1:320 and 1:2560) were added per well and incubated for $1 \mathrm{~h}$ at RT. Plates were washed three times with $200 \mu \mathrm{L}$ PBST (PBS with $0.05 \%$ Tween 20) and then HRP-conjugated cross-adsorbed anti-human IgG secondary antibody (Thermo Fisher A18823, Waltham, MA, USA) was added at $1: 20,000$ and incubated for $1 \mathrm{~h}$ at RT. Plates were washed five times with $200 \mu \mathrm{L}$ PBST and once with $200 \mu \mathrm{L}$ PBS; then developed with TMB for 6-7 min before being stopped by adding 0.16 molar sulfuric acid. Absorbance was read at $450 \mathrm{~nm}$.

A standard curve was generated using a humanized anti-spike receptorbinding-domain monoclonal antibody of known concentration (Sino Biological 40150-D001) and run on each ELISA plate. Four-parameter logistical regression was used to convert absorbance signal from each well to ng antibody/well based on the known ng from the standard curve. Each patient's sera from all three timepoints were run on the same plate. Samples were quantified using the 1:320 dilution if spike-binding antibody levels were $<10 \mu \mathrm{g} / \mathrm{mL}$, and with the $1: 2560$ if levels were $>10 \mu \mathrm{g} / \mathrm{mL}$. The total measurable linear range of ELISA quantification based on the standard curve was $0.44-284 \mu \mathrm{g} / \mathrm{mL}$, which was further extended to as low as $0.03 \mu \mathrm{g} / \mathrm{mL}$ by use of $1: 40$ dilutions for selected samples. Serum values were converted into WHO international units based on the 20/136 standard of $1000 \mathrm{IU} / \mathrm{mL}$, which we quantified in quadruplicate and found to correspond to $88 \mu \mathrm{g} / \mathrm{mL}$ of spike-binding antibodies (thus $1 \mu \mathrm{g} / \mathrm{mL}=11.4 \mathrm{IU} / \mathrm{mL}$ ).

\section{Statistical analysis}

The nonparametric two-sided Mann-Whitney $U$ test was used for pairwise comparisons of distributions between groups. We used the Kruskal-Wallis test to determine differences between MM heavy chain type and races. $P<$ 0.05 was considered statistically significant. Predictors of vaccine response were found using a multivariate ordinal logistic regression model with stepwise variable selection. Vaccine response was separated into no response $(<50 \mathrm{IU} / \mathrm{mL})$, partial response $(50-250 \mathrm{IU} / \mathrm{mL})$, and clinically relevant response $>250 \mathrm{IU} / \mathrm{mL}$ ). $P<0.1$ determined if a variable was included in the model. Statistical analysis was performed using GraphPad Prism 9 (San Diego, CA) and R (version 4.0.3).

\section{RESULTS}

\section{Efficacy of COVID-19 vaccine in MM patients}

Overall, 103 MM patients ( 96 patients with active MM and 7 with smoldering disease) and 31 healthy subjects who received two doses of mRNA-based COVID-19 vaccines (BNT162b2 or mRNA1273) were included in the study. Serum obtained during the preCOVID era (May 9, 2016 to March 15, 2019) from 34 healthy subjects was used to establish the assay background. Baseline characteristics of all participants are shown in Table 1. For patients, the median age was 68 years, $59 \%$ of patients were male, and $73 \%$ were Caucasian. Active MM patients were treated with a variety of anti-MM agents, including steroid-containing therapy (91\%), proteasome inhibitors (44\%), and immunomodulatory agents

Table 1. Patient characteristics and treatments.

\begin{tabular}{|c|c|c|c|c|c|c|c|c|}
\hline & $\begin{array}{l}\text { Total } \\
\text { patients }\end{array}$ & $\begin{array}{l}\operatorname{lgA} M^{M^{a}} \\
\text { patients }\end{array}$ & $\begin{array}{l}\text { IgG MM } \\
\text { patients }\end{array}$ & $\begin{array}{l}\text { Light chain } \\
\text { MM } \\
\text { patients }\end{array}$ & $\begin{array}{l}\text { Other' }{ }^{b} \text { MM } \\
\text { patients }\end{array}$ & $\begin{array}{l}\text { SMM }^{\mathrm{C}} \\
\text { patients }\end{array}$ & $\begin{array}{l}\text { Healthy } \\
\text { controls }\end{array}$ & $\begin{array}{l}\text { Pre-COVID- } \\
19 \text { controls }\end{array}$ \\
\hline Number of subjects & 103 & 18 & 48 & 24 & 6 & 7 & 31 & 34 \\
\hline Median age (range) & $68(35-88)$ & $67(50-88)$ & $68(47-88)$ & $69(39-86)$ & $59(35-87)$ & $69(49-79)$ & $61(26-85)$ & $64(30-87)$ \\
\hline $\begin{array}{l}\text { Race (Caucasian/AA } / \\
\text { Hispanic/Asian/ME }{ }^{\mathrm{d}} \text { ) }\end{array}$ & $75 / 7 / 5 / 8 / 8$ & $12 / 0 / 4 / 1 / 1$ & $35 / 5 / 0 / 4 / 4$ & $18 / 2 / 1 / 0 / 3$ & $3 / 0 / 0 / 3 / 0$ & $7 / 0 / 0 / 0 / 0$ & $28 / 0 / 1 / 0 / 0$ & $23 / 1 / 2 / 4 / 1$ \\
\hline Proteasome inhibitor (PI) & $45(44)$ & $8(44)$ & $22(46)$ & $13(54)$ & $2(33)$ & $0(0)$ & N/A & N/A \\
\hline $\begin{array}{l}\text { Immunomodulatory } \\
\text { agents (IA) }\end{array}$ & $39(38)$ & $6(33)$ & $23(48)$ & $8(33)$ & $2(33)$ & $0(0)$ & N/A & N/A \\
\hline $\mathrm{PI}+\mathrm{IA}$ & $11(11)$ & $3(17)$ & $6(13)$ & $2(8)$ & $0(0)$ & $0(0)$ & N/A & N/A \\
\hline Antibodies & $19(18)$ & $5(28)$ & $8(17)$ & $5(21)$ & $1(17)$ & $0(0)$ & $\mathrm{N} / \mathrm{A}$ & N/A \\
\hline
\end{tabular}

NA not applicable.

${ }^{a}$ Multiple myeloma.

${ }^{\mathrm{b}}$ Two IgM, IgD, and nonsecretory patients each.

'Smoldering multiple myeloma.

${ }^{\mathrm{d}}$ African American.

${ }^{\mathrm{e}}$ Middle Eastern. 
(38\%; Table 1). MM patients' baseline laboratory values reflecting their disease status are shown in Supplementary Table 1.

Prevaccination baseline levels of spike antibodies were the lowest among $\mathrm{MM}$ patients (median $=7.3 \mathrm{IU} / \mathrm{mL}, p<0.0001$ ) compared to healthy subjects who received COVID-19 vaccination (median $=30.5 \mathrm{IU} / \mathrm{mL}$ ) and pre-COVID-19-era subjects (median = $21.9 \mathrm{IU} / \mathrm{mL}$; Fig. 1A; Table 2). Since a few subjects developed very high antibody levels which skewed the group averages, we report the median instead of the mean. Patients with active MM had a significantly diminished response (median $=173.7 \mathrm{IU} / \mathrm{mL}$ ) compared to those with smoldering MM $(n=7 ;$ median $=555.8$ $\mathrm{IU} / \mathrm{mL} ; p=0.0311)$ and healthy subjects $(n=31$; median $=893.6$ $\mathrm{IU} / \mathrm{mL} ; p<0.001$; Fig. $1 \mathrm{~B}$; Table 2). Given that all smoldering MM patients responded fully to vaccination and were not receiving antimyeloma treatment, the remainder of the analyses were limited to the 96 patients with active myeloma.

Patient responses were categorized into the following three categories: likely clinically relevant response with spike antibody levels $>250 \mathrm{IU} / \mathrm{mL}$, partial response $(50-250 \mathrm{IU} / \mathrm{mL})$, and negative response $(<50 \mathrm{IU} / \mathrm{mL}$; Fig. $1 \mathrm{C})$. The clinically relevant cutoff of
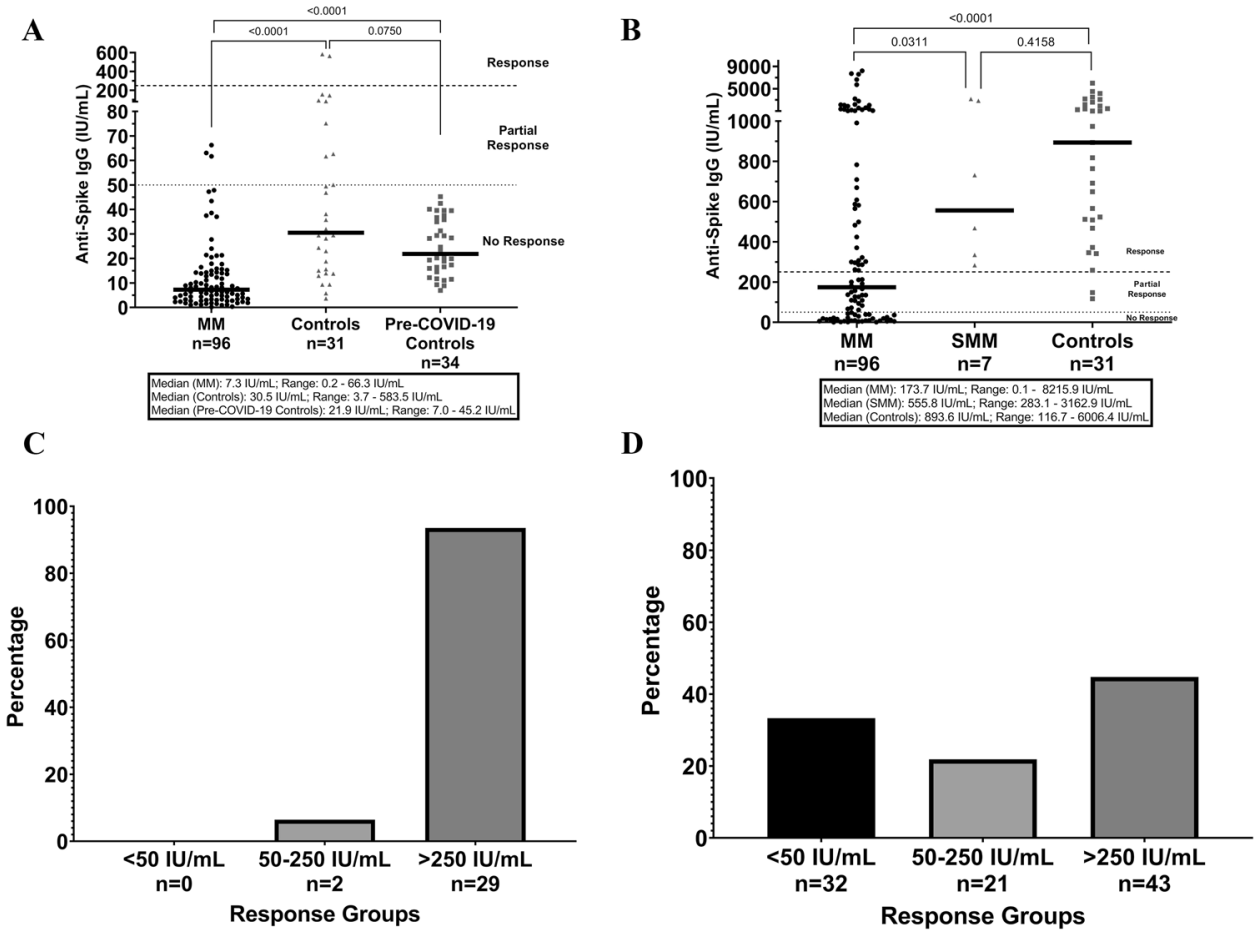

Fig. 1 Anti-SARS-CoV-2 spike IgG levels. Anti-SARS-CoV-2 spike IgG levels were measured prior to vaccination (A) in multiple myeloma patients (MM), age-matched controls, and separately tested on banked sera from before the COVID-19 era. Postvaccination IgG levels were drawn 14-21 days after the second dose (B) in MM, smoldering multiple myeloma (SMM), and age-matched healthy subjects. Participants were stratified as nonresponders if they did not exceed pre-COVID-19 antibody levels $(50 \mathrm{lU} / \mathrm{mL}$, lower dotted line), partial responders if they failed to exceed the bottom 6th percentile of healthy controls $(250 \mathrm{IU} / \mathrm{mL}$, upper dashed line), and clinically significant responders if above $250 \mathrm{IU} / \mathrm{mL}$. Relative percentages of controls (C) and MM patients (D) fell into these three distinct groups.

Table 2. Anti-spike lgG levels.

\begin{tabular}{|c|c|c|c|c|c|c|c|c|}
\hline & $\begin{array}{l}\text { Total } \mathrm{MM}^{\mathrm{a}} \\
\text { patients }\end{array}$ & $\begin{array}{l}\text { IgA MM } \\
\text { patients }\end{array}$ & $\begin{array}{l}\text { IgG MM } \\
\text { patients }\end{array}$ & $\begin{array}{l}\text { Light chain } \\
\text { MM patients }\end{array}$ & $\begin{array}{l}\text { Other' MM } \\
\text { patients }\end{array}$ & $\begin{array}{l}\text { SMMC }^{\mathrm{C}} \\
\text { patients }\end{array}$ & $\begin{array}{l}\text { Healthy } \\
\text { controls }\end{array}$ & $\begin{array}{l}\text { Pre-COVID- } \\
19 \text { controls }\end{array}$ \\
\hline \multicolumn{9}{|l|}{$\begin{array}{l}\text { Anti-spike IgG levels } \\
\text { (IU/mL) }\end{array}$} \\
\hline Baseline median & 7.28 & 8.35 & 5.79 & 7.96 & 12.06 & 22.25 & 30.50 & 21.85 \\
\hline $\begin{array}{l}\text { Baseline standard } \\
\text { deviation }\end{array}$ & 13.83 & 8.84 & 15.40 & 15.31 & 6.62 & 11.48 & 137.84 & 11.38 \\
\hline $\begin{array}{l}\text { D1 standard } \\
\text { deviation }\end{array}$ & 297.25 & 49.24 & 417.86 & 51.17 & 36.51 & 81.66 & 584.38 & N/A \\
\hline D2 median & 173.72 & 304.16 & 136.02 & 178.87 & 2077.77 & 555.78 & 893.6 & N/A \\
\hline $\begin{array}{l}\text { D2 standard } \\
\text { deviation }\end{array}$ & 1653.32 & 1883.30 & 1793.42 & 530.06 & 2614.65 & 1245.66 & 1474.76 & N/A \\
\hline
\end{tabular}

NA not applicable.

aMultiple myeloma.

${ }^{\mathrm{b}} \mathrm{Tw}$ o IgM, IgD, and nonsecretory patients each.

'Smoldering multiple myeloma. 


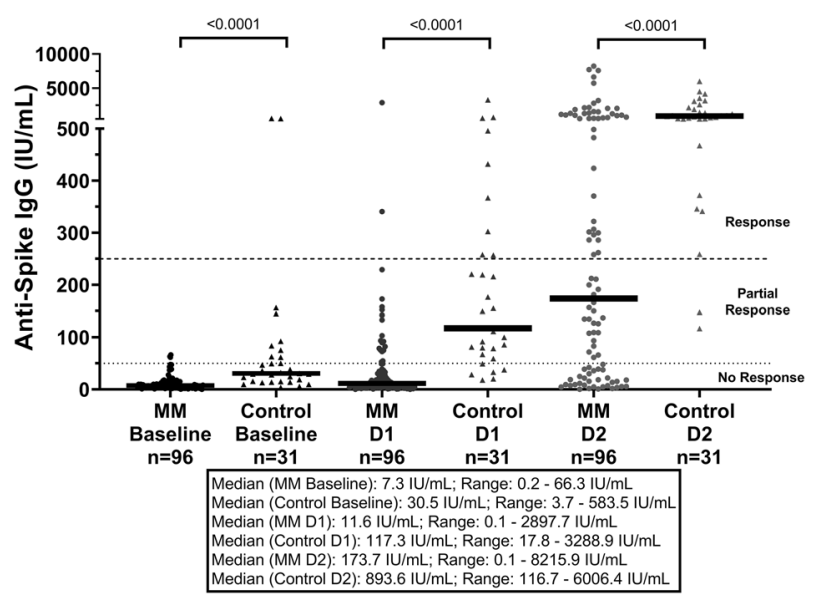

Fig. 2 Comparison of anti-SARS-CoV-2 spike IgG levels between controls and MM patients. Anti-SARS-CoV-2 spike lgG levels measured at baseline, D1 (12-21 days after first dose of vaccine), and D2 (14-21 days after second dose). The lower dotted line at $50 \mathrm{IU} / \mathrm{mL}$ is the cutoff between nonresponse and partial response, with the upper dashed line at $250 \mathrm{IU} / \mathrm{mL}$ as the cutoff to achieve an expected clinically significant response.

$250 \mathrm{IU} / \mathrm{mL}$ was selected based on the previously reported $94-95 \%$ efficacy data of the mRNA vaccination against mild COVID-19 cases $[15,16]$, and corresponded to a spike antibody level that was exceeded by $94 \%$ of the control samples in our study (Figs. 1C and 2). A longitudinal study of 246 dental professionals who had COVID19 revealed that spike antibody levels of $>147 \mathrm{IU} / \mathrm{mL}$ conferred complete protection against reinfection during a 6-month follow-up, consistent with the clinical relevance of our selected $250 \mathrm{IU} / \mathrm{mL}$ cutoff [17]. The $50 \mathrm{IU} / \mathrm{mL}$ cutoff for partial responders was selected based on the assay's background assessment using 34 healthy patients' sera drawn before the COVID-19 era, none of whom exceeded this threshold (Fig. 1A and Table 2). Based on these cutoffs, $45 \%(n=43)$ of MM patients had a likely clinically significant response $>250 \mathrm{IU} / \mathrm{mL}$, with an additional $22 \%(n=21)$ having a partial response (Fig. 1D). Of the $33 \%$ of patients $(n=32)$ who did not respond above background, 9 had at least a fivefold response over their baseline levels, suggesting their immune system may have minimally responded.

Serum samples collected 12-21 days after the first dose (14-21 days for all but three patients) allowed us to evaluate the effect of single vaccine dosing. Only $2(2 \%)$ patients developed clinically significant immunity $(>250 \mathrm{lU} / \mathrm{mL}$ ) after one dose, with an additional 18 (19\%) showing partial protection (50-250 IU/mL; Fig. 2). Levels increased after the second dose with $43(45 \%)>250 \mathrm{IU} / \mathrm{mL}$ and $21(22 \%)$ patients at $50-250 \mathrm{IU} / \mathrm{mL}$ (Figs. 1B and 2).

\section{Correlation between the efficacy of COVID-19 vaccine and demographic and clinical characteristics}

We determined whether the MM patients' age, sex, and race affected the efficacy of vaccination. Younger patients ( $<68$ years) developed higher anti-spike IgG levels (Fig. 3A). Neither sex nor race correlated with vaccine response although the numbers of patients in the non-Caucasian groups were small (data not shown).

Baseline laboratory characteristics of the MM patients were also correlated with vaccine efficacy. Patients with elevated creatinine levels (>1.3 mg/dL) had lower antibody levels (Fig. 3B). Hemoglobin level and neutrophil and platelet counts were not associated with vaccine response (data not shown) but those with low lymphocyte counts had inferior responses (Fig. 3C).

The Ig type of MM and levels of M-protein and involved serumfree light chain (sFLC) were not correlated with response (data not shown). In contrast, patients with reduced levels of uninvolved
A

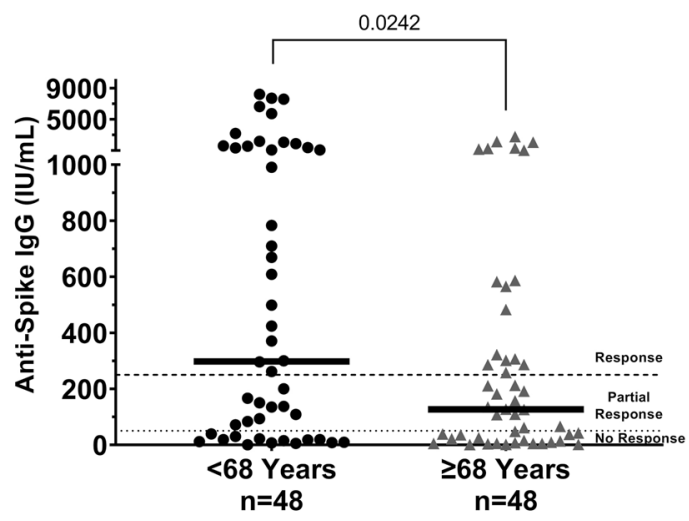

Median (<68 Years): $297.9 \mathrm{IU} / \mathrm{mL}$; Range: $0.1-8215.9 \mathrm{IU} / \mathrm{mL}$ Median ( $\geq 68$ Years): $126.6 \mathrm{IU} / \mathrm{mL}$; Range: $0.6-2795.5 \mathrm{IU} / \mathrm{mL}$

B
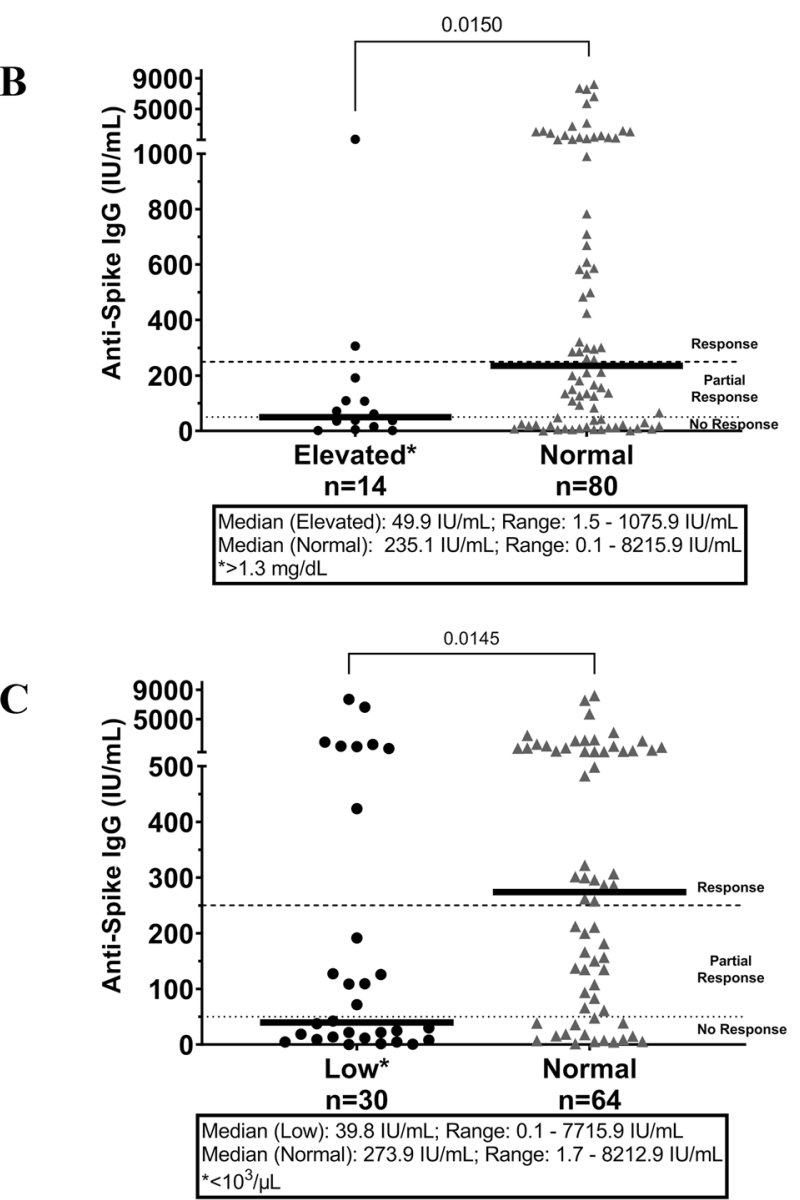

Fig. 3 Correlation between anti-SARS-CoV-2 spike IgG levels and demographic and clinical characteristics. D2 anti-spike lgG levels were stratified by age above or below the median (A), creatinine at an elevated level of $>1.3 \mathrm{mg} / \mathrm{dL}$ vs normal (B), and low lymphocyte count $<10^{3} / \mu \mathrm{L}$ vs normal (C). Dotted and dashed lines indicate 50 and $250 \mathrm{IU} / \mathrm{mL}$

IgG, IgA, IgM, or sFLC lambda all developed lower amounts of antispike antibody compared to those with normal levels (uninvolved IgG [median 132.2 vs $516.1 \mathrm{IU} / \mathrm{mL} ; p=0.0131$; Fig. 4A], IgA [median 101.2 vs $658.9 \mathrm{IU} / \mathrm{mL} ; p<0.0001$; Fig. 4B], IgM [median 51.7 vs $576.2 \mathrm{IU} / \mathrm{mL} ; p<0.0001$; Fig. $4 \mathrm{C}$ ], and sFLC lambda [median 90.3 vs $306.7 \mathrm{IU} / \mathrm{mL} ; p=0.0419$; Fig. 4D]). Only three patients had decreased uninvolved sFLC kappa levels.

Patients were treated with a variety of therapies at the time of vaccination (Table 1) and, therefore, the correlation between the 
A

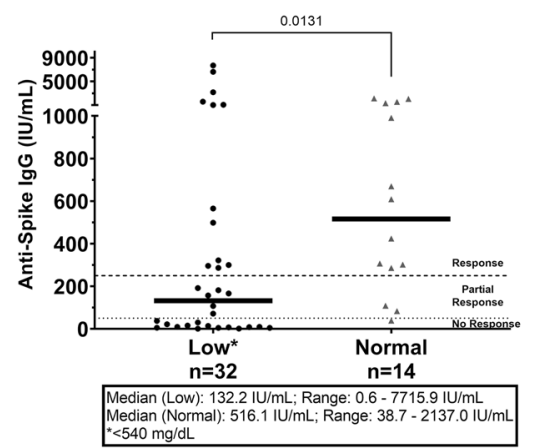

C

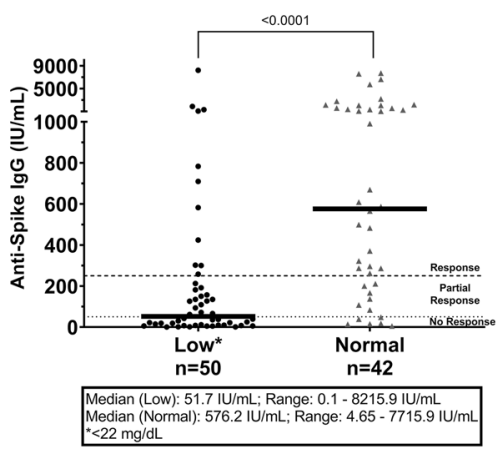

B

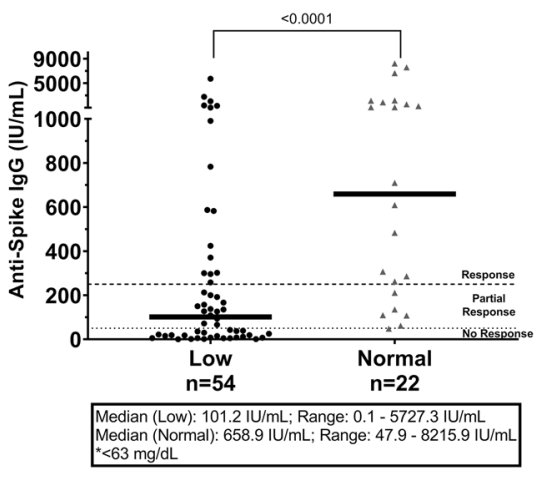

D

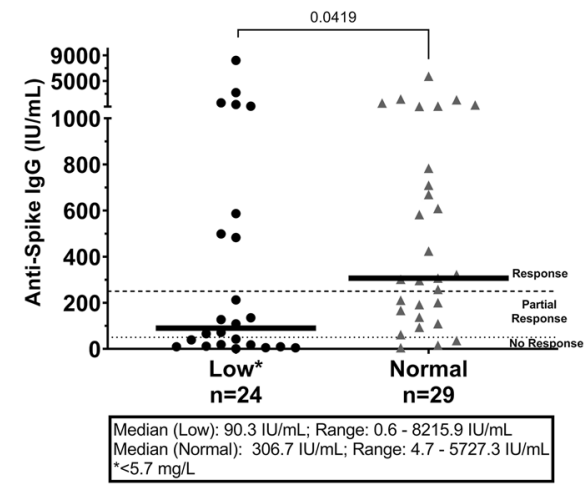

Fig. 4 Correlation between uninvolved immunoglobulins and antispike IgG. D2 anti-spike lgG levels among MM patients stratified by baseline total uninvolved IgG (A), $\operatorname{lgA}(\mathbf{B}), \lg M(\mathbf{C})$, and lambda serum-free light chains (D). Dotted and dashed lines indicate 50 and $250 \mathrm{IU} / \mathrm{mL}$.

treatment type and vaccine response was examined. No correlation between any specific treatment type and vaccine response was observed (Supplementary Fig. 1) except those receiving steroids had reduced antibody levels compared to those who were not $(p=0.0354)$, but only nine patients were in the latter group. Patients on frontline therapy produced higher anti-spike antibody levels (median $443.7 \mathrm{IU} / \mathrm{mL}$ ) than previously treated patients on therapy (median $126.0 \mathrm{IU} / \mathrm{mL} ; p=0.0189$; Fig. $5 \mathrm{~A}$ ). Furthermore, MM patients with a complete response (CR) achieved higher antibody levels (median $489.4 \mathrm{IU} / \mathrm{mL}$ ) than those who were not in $\mathrm{CR}$ (median $117.4 \mathrm{IU} / \mathrm{mL} ; p=0.0027$; Fig. 5B). In addition, patients with at least a partial response to MM therapy (PR; median $210.8 \mathrm{IU} / \mathrm{mL}$; Fig. 5C) had higher antibody levels than those with stable or progressive disease (median $40.6 \mathrm{IU} / \mathrm{mL} ; p=$ 0.0520 ). Thus, more advanced disease and worse disease status were indicative of a poorer response to COVID-19 mRNA vaccination.

\section{Comparison between efficacy of mRNA-1273 (Moderna) and BNT162b2 (Pfizer) vaccines}

Half of the MM patients in this study were vaccinated with mRNA1273 (Moderna) and the remaining patients with BNT162b2 (Pfizer/ BioNTech). mRNA-1273-vaccinated patients developed higher antispike antibody levels after two doses of vaccination (median 346.2 $\mathrm{IU} / \mathrm{mL}$ vs $100.6 \mathrm{IU} / \mathrm{mL} ; p=0.0031$; Fig. $6 \mathrm{~A}$ ), with $30 / 48$ (63\%) patients in the mRNA-1273 group achieving antibody levels $>250 \mathrm{IU} / \mathrm{mL}$ compared to only $13 / 48(27 \%)$ of those who received BNT162b2 (Fig. 6B). This occurred even with near-identical baseline levels in the two vaccination groups. Compared with baseline, mRNA-1273 was associated with a larger fold increase than BNT162b2 in antibody levels following both the first and second vaccinations (Fig. 6C). Controls who received mRNA-1273 also produced higher antibody levels, but this may have occurred partially because of higher baseline levels among those subjects, which could have indicated a higher rate of prior COVID-19 infection in the mRNA-1273vaccinated controls (Supplementary Fig. 2).

\section{Multivariate analysis}

Among these patients, many parameters predicting vaccine response were interdependent, often relating to immune system function. Multivariate analysis with stepwise variable selection was used to assess which variables were truly independent. The following variables were evaluated: low hemoglobin, low neutrophil and lymphocyte counts, age, elevated serum creatinine, serum $M$-protein, difference between involved and uninvolved sFLC levels, low uninvolved IgA, lgG, IgM, and sFLC levels, frontline vs salvage therapy, and mRNA-1273 vs BNT162b2 vaccines. Since data regarding some of the predictors of response were unavailable on eight patients, a final sample size of 88 patients was analyzed. After stepwise variable selection, low uninvolved $\operatorname{lgM}(p<0.001)$ and mRNA-1273 $(p=0.014)$ were predictive of vaccine response.

\section{Breakthrough case}

One patient vaccinated with mRNA-1273 was diagnosed with severe COVID-19 10 weeks following his second vaccination. His antibody level increased to $608 \mathrm{IU} / \mathrm{mL} 2$ weeks following his second vaccination but then decreased to $126 \mathrm{IU} / \mathrm{mL}$ after another 6 weeks. Four days later, he was directly exposed to two individuals who developed symptomatic COVID-19 infections requiring hospitalization. Eleven days later, he was febrile and hypoxic and tested positive for SARS-CoV-2 (data not shown). This case illustrates that antibody responses among MM patients may be more transitory than in immune competent individuals, placing them at higher risk to develop symptomatic COVID-19 infection. More frequent antibody monitoring may be required for these patients.

\section{DISCUSSION}

We demonstrate that two-thirds of MM patients do have some response to vaccination with mRNA vaccines, but many develop levels that likely provide only partial protection. There is currently 
A

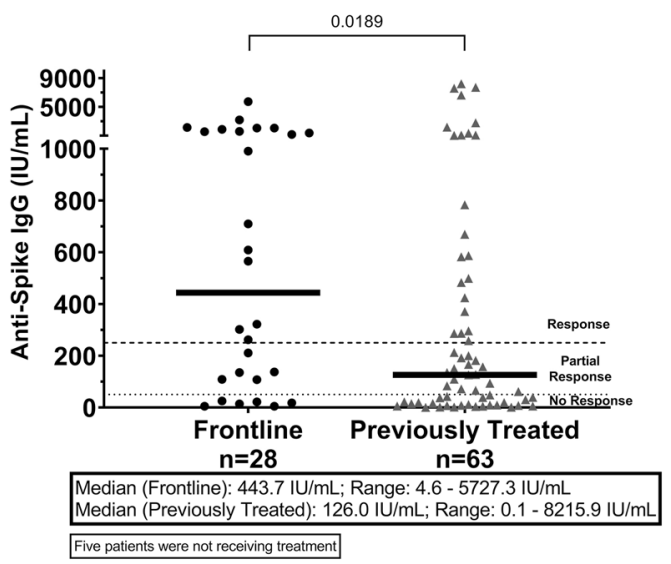

B

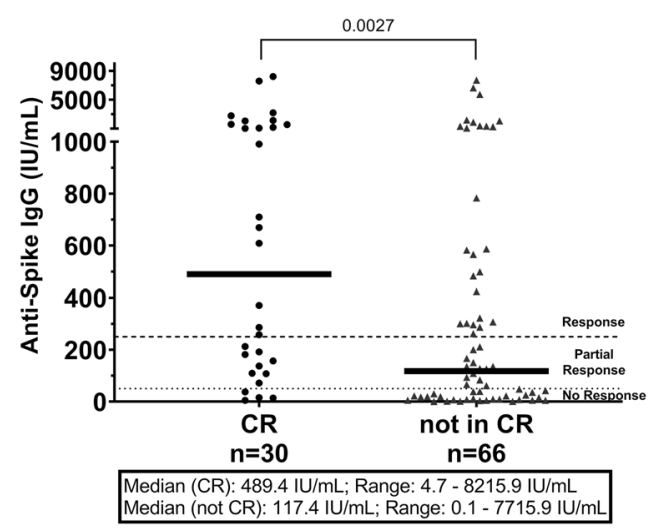

C

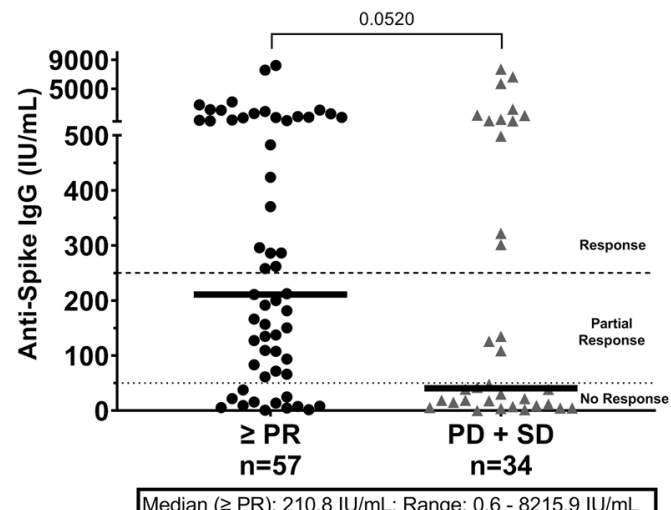

Median (PD+SD): $40.6 \mathrm{IU} / \mathrm{mL}$; Range: $0.1-7715.9 \mathrm{IU} / \mathrm{mL}$

Fig. 5 D2 anti-spike IgG levels among MM patients stratified based on the clinical status. D2 anti-spike IgG levels among MM patients stratified by treatment stage $(\mathbf{A})$, presence or absence of complete response (CR) to myeloma treatment (B), and partial response or better $(\geq P R)$ vs stable or progressive disease (PD + SD) (C). Dotted and dashed lines indicate 50 and $250 \mathrm{IU} / \mathrm{mL}$.

no clearly defined level of antibody that identifies protection, making it difficult to determine to what degree patients are susceptible to COVID-19 based on their vaccine response. Nonhuman primate models are difficult to extrapolate to realworld situations, as they are typically infected with $>500,000$ PFU of virus, resulting in infection even in fully vaccinated animals $[18,19]$. Real-world exposures are likely much lower and more probable to induce subclinical infections even in unvaccinated individuals. We selected $>250 \mathrm{lU} / \mathrm{mL}$ as antibody levels likely to confer clinically significant protection on the basis that $94 \%$ of our
A

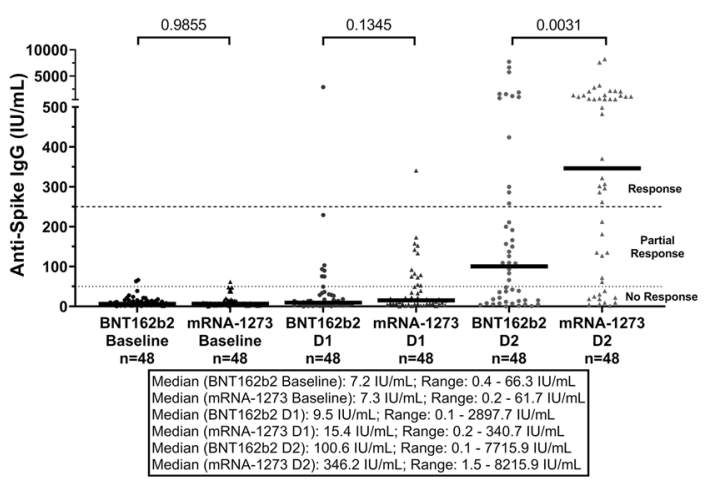

B

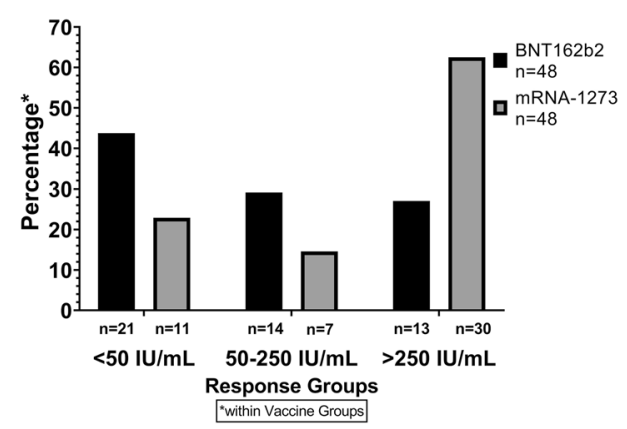

C

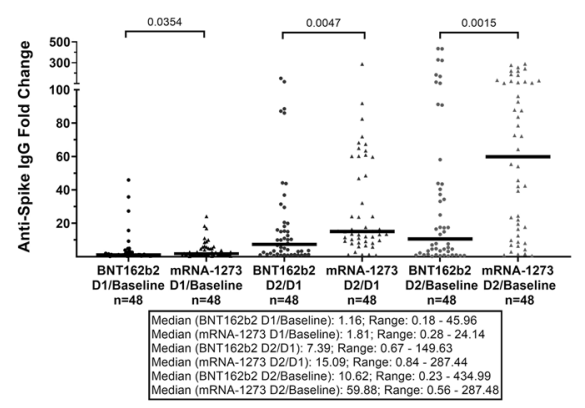

Fig. 6 Anti-spike IgG levels among MM patients stratified based on the type of mRNA vaccine received. Anti-spike IgG levels among MM patients at baseline, D1, and D2, stratified by type of mRNA vaccine (mRNA-1273 [Moderna] or Bnt162b2 [Pfizer/BioNTech] received (A), with dotted and dashed lines indicating 50 and $250 \mathrm{IU} / \mathrm{mL}$, respectively. D2 spike IgG levels were subdivided by response group and vaccine type (B). Anti-spike lgG levels increased with successive doses and were divided by either the baseline spike IgG level or D1 IgG level to determine the fold change in spike antibody levels with successive dosing (C).

controls achieved this level, along with others' data showing that COVID-19 survivors with $>147 \mathrm{IU} / \mathrm{mL}$ did not develop any reinfections in a 6-month follow-up period [17]. Clinical validation of this metric was demonstrated within our own study after a myeloma patient with a spike antibody level that decreased to $126 \mathrm{IU} / \mathrm{mL}$ developed severe COVID-19 that did not require hospitalization, suggesting that this level provided him with only incomplete protection. The MM patients (22\%) with spike antibody levels between 50 and $250 \mathrm{IU} / \mathrm{mL}$ all fall within this category, which may provide some protection against critical illness but likely leaves them still susceptible to lower-grade disease. As more variants emerge with increased immune escape, this incomplete protection becomes even more clinically relevant, putting patients at increased risk for hospitalization and death. Given their intermediate response to the initial two-dose series, revaccinations for COVID-19 should be considered in this group, possibly with a different vaccine or at a higher dose. This tactic has 
been used successfully with hepatitis B revaccination, which resulted in seroconversion for $70 \%$ of HIV-positive patients who had not responded to initial vaccination. Higher hepatitis B surface antibody levels were observed among those receiving a double dose vaccine [20].

The one-third of MM patients who failed to respond above background levels of $50 \mathrm{lU} / \mathrm{mL}$ remain at high risk for COVID-19 infection and even death. They should be considered for prophylactic infusions of anti-SARS-CoV-2 monoclonal antibodies or intermittent Ig infusions. Some of these vaccine failure patients did have some increase in spike antibody levels after their vaccinations and perhaps these individuals might also be candidates for revaccination strategies. Consistent with risk factors for infection among MM patients [6-12], impaired renal function, lower absolute lymphocyte and uninvolved lg levels, and more advanced myeloma disease were associated with decreased antibody levels following vaccination. MM patients who achieve CRs to treatment can normalize their uninvolved Ig levels unlike most other patients and overall are known to have improved outcomes [21]. Vaccination at that time may produce improved antibody responses to vaccination.

Higher COVD-19 antibody levels were achieved among MM patients vaccinated with mRNA-1273 compared to BNT162b2. These vaccines encode nearly identical products, but mRNA-1273 contains $100 \mu \mathrm{g}$ of mRNA, compared to only $30 \mu \mathrm{g}$ in BNT162b2. This could account for the increased antibody levels among the MM patients who received mRNA-1273, similar to results seen in dose-escalation trials in healthy individuals $[18,22]$ and in spike antibody measurements after routine vaccination [23]. Our healthy controls who received mRNA-1273 did have higher antibody levels than those receiving BNT162b2, but this was confounded by higher baseline spike IgG levels in the mRNA-1273 group. Regardless, the difference is unlikely to be clinically significant among healthy individuals as phase III trials for both mRNA vaccines demonstrated a similar degree of clinical protection against mild disease. However, for MM patients, the difference between these two vaccines may be more consequential, as patients receiving mRNA-1273 were much more likely to reach antibody levels $>250 \mathrm{IU} / \mathrm{mL}$ than those who received BNT162b2 (63\% vs $27 \%)$, possibly making it the preferred option for patients with active myeloma.

After the first mRNA vaccine dose, we observed only $2 \%$ of MM patients with spike antibody levels of $>250 \mathrm{IU} / \mathrm{mL}$, and just $19 \%$ of patients at levels above background $(>50 \mathrm{IU} / \mathrm{mL})$. This contrasts with an earlier report, which indicated that $56 \%$ of myeloma patients had positive lgG levels 21 days after a single vaccine dose [24]. This difference is unlikely to be due to patient sera being drawn earlier, as another study demonstrated that patients sampled at 13-16 days after the first dose of mRNA vaccines had $78 \%$ of the antibody levels as those sampled at $21-28$ days [25]. Rather, this is more likely due to a different cutoff selection in the commercial IgG assay used by Bird et al. [24]. The phase III clinical trials for both mRNA vaccines demonstrated that there was clinically significant protection from COVID-19 as early as 14 days after the first dose $[15,16]$. This has provided the justification for delayed second vaccinations. Our assay suggests that this strategy is not appropriate for myeloma patients, especially for those who did not generate strong antibody responses to the first dose.

This study has several limitations. While participants with PCRconfirmed COVID-19 were excluded, we could not determine whether some had undiagnosed prior COVID-19. Previous infection leads to a more robust vaccine response, particularly following the first dose [25], and likely led to some patients and controls developing higher anti-spike antibody levels than what they would otherwise have achieved without prior exposure. Indeed, the controls and patients who responded the best to the first dose tended to have higher baseline levels, suggestive of possible preexisting infection. Unfortunately, not all COVID-19 survivors have detectable anti-spike IgG [26], and it cannot consistently be used as a surrogate for prior infection. MM patients, with their lack of normal antibody-producing plasma cells, are more likely than controls to have anti-spike lgG levels not indicative of COVID-19 following infection. Since we could not reliably exclude patients because of elevated baseline anti-spike lgG levels, we elected to include all patients. In this manner, our results are more generalizable, as most individuals receiving COVID-19 vaccination have not been prescreened with anti-spike lgG levels.

There is still no clear level for defining protection in vaccinated individuals. As a result, our cutoffs of $50-250 \mathrm{IU} / \mathrm{mL}$ for partial response and $>250 \mathrm{IU} / \mathrm{mL}$ for clinically significant response are somewhat arbitrary. We did not evaluate patients for spike-specific T cells, which likely provide additional clinically significant protection that may not fully correlate with spike IgG levels. While our cohort of 96 active myeloma patients is one of the largest thus far to be assessed-especially at baseline and after each of the two vaccinations-it still represents individuals with varying degrees of disease severity and who were receiving a variety of different therapeutic regimens. This artificially simplifies the pool of highly variable immunologically complex MM patients. While $45 \%$ of patients in our study developed spike antibody levels of $>250 \mathrm{IU} / \mathrm{mL}$, most individual MM patients either have a much higher or much lower probability of responding to vaccination, which is likely based on the current status of their disease and immune system, and not simply their status of having active myeloma.

Overall, $55 \%$ of MM patients failed to fully respond to COVID-19 vaccination. Low baseline IgM levels were most predictive of incomplete responses to the vaccines, while vaccination with mRNA-1273 resulted in higher anti-spike antibody levels than BNT162b2 in this population. Based on these data, myeloma patients may need to continue social distancing following COVID19 vaccination, and postvaccine spike IgG levels may help guide decisions regarding future revaccination strategies and/or antibody prophylaxis for this vulnerable population.

\section{DATA AVAILABILITY}

For original data, please contact JRB at jberenson@berensoncancercenter.com or SDS at s.stampfer@gmail.com.

\section{REFERENCES}

1. World Health Organization. (2021, July 27). WHO coronavirus (COVID-19) Dashboard. https://covid19.who.int/.

2. O'Driscoll M, Ribeiro Dos Santos G, Wang L, Cummings DAT, Azman AS, Paireau J, et al. Age-specific mortality and immunity patterns of SARS-CoV-2. Nature. 2021; 590:140-45.

3. Lee LYW, Cazier JB, Starkey T, Briggs SEQ, Arnold R, Bisht V, et al. COVID-19 prevalence and mortality in patients with cancer and the effect of primary tumour subtype and patient demographics: a prospective cohort study. Lancet Oncol. 2020;21:1309-16.

4. Ludwig H, Boccadoro M, Moreau P, San-Miguel J, Cavo M, Pawlyn C, et al. Recommendations for vaccination in multiple myeloma: a consensus of the European Myeloma Network. Leukemia. 2021;35:31-44.

5. Blimark C, Holmberg E, Mellqvist UH, Landgren O, Biorkholm M, Hultcrantz $M$, et al. Multiple myeloma and infections: a population-based study on 9253 multiple myeloma patients. Haematologica. 2015;100:107-13.

6. Hargreaves RM, Lea JR, Griffiths H, Faux JA, Hebbel RP, Oken MM, et al. Immunological factors and risk of infection in plateau phase myeloma. J Clin Pathol. 1995;48:260-6.

7. Perri RT, Hebbel RP, Oken MM. Influence of treatment and response status on infection risk in multiple myeloma. Am J Med. 1981;71:935-40.

8. Sørrig R, Klausen TW, Salomo M, Vangsted A, Gimsing P. Risk factors for infections in newly diagnosed multiple myeloma patients: a Danish retrospective nationwide cohort study. Eur J Haematol. 2019;102:182-90.

9. Teh BW, Harrison SJ, Pellegrini M, Thursky KA, Worth U, Slavin MA. Changing treatment paradigms for patients with plasma cell myeloma: impact upon immune determinants of infection. Blood Rev. 2014;28:75-86. 
10. Johnsrud A, Susanibar S, Kamimoto JJ, Johnsrud AJ, Kothari A, Burgess MJ, et al. Infectious complications of daratumumab-containing therapy for multiple myeloma. Blood. 2017;130:3148.

11. Girmenia C, Cavo M, Offidani M, Scaglione F, Corso A, Raimondo DF, et al Management of infectious complications in multiple myeloma patients: expert panel consensus-based recommendations. Blood Rev. 2019;34:84-94.

12. Jung Y, Kim JK, Shiozawa Y, Wang J, Mishra A, Joseph J, et al. Recruitment of mesenchymal stem cells into prostate tumours promotes metastasis. Nat Commun. 2013;4:1795.

13. Corbett KS, Edwards DK, Leist SR, Abiona OM, Boyoglu-Barnum S, Gillespie RA, et al. SARS-CoV-2 mRNA vaccine design enabled by prototype pathogen preparedness. Nature. 2020;586:567-71.

14. Walsh EE, Frenck RW Jr, Falsey AR, Kitchin N, Absalon J, Gurtman A, et al. Safety and immunogenicity of two RNA-based Covid-19 vaccine candidates. N Engl J Med. 2020;383:2439-50.

15. Polack FP, Thomas SJ, Kitchin N, Absalon J, Gurtman A, Lockhart S, et al. Safety and efficacy of the BNT162b2 mRNA Covid-19 vaccine. N Engl J Med. 2020;383:2603-15.

16. Baden LR, El Sahly HM, Essink B, Kotloff K, Frey S, Novak R, et al. Efficacy and safety of the mRNA-1273 SARS-CoV-2 vaccine. N Engl J Med. 2021;384:403-16.

17. Shields AM, Faustini SE, Kristunas CA, Cook AM, Backhouse C, Dunbar L, et al. COVID-19: Seroprevalence and Vaccine Responses in UK Dental Care Professionals. J Dental Res. 2021. https://doi.org/10.1177/00220345211020270.

18. Jackson LA, Anderson EJ, Rouphael NG, Roberts PC, Makhene M, Coler RN, et al. An mRNA vaccine against SARS-CoV-2-preliminary report. $\mathrm{N}$ Engl J Med. 2020;383:1920-31.

19. Corbett KS, Nason MC, Flach B, Foulds KE, Francica JR, Boyoglu-Barnum S, et al. Immune correlates of protection by mRNA-1273 immunization against SARS-CoV2 infection in nonhuman primates. 2021. Preprint.

20. Rey D, Piroth L, Wendling MJ, Miailhes P, Michel ML, Dufour C, et al. Safety and immunogenicity of double-dose versus standard-dose hepatitis $B$ revaccination in non-responding adults with HIV-1 (ANRS HB04 B-BOOST): a multicentre, openlabel, randomised controlled trial. Lancet Infect Dis. 2015;15:1283-91.

21. Kastritis E, Zagouri F, Symeonidis A, Roussou M, Sioni A, Pouli A, et al. Preserved levels of uninvolved immunoglobulins are independently associated with favorable outcome in patients with symptomatic multiple myeloma. Leukemia. 2014;28:2075-9.

22. Mulligan MJ, Lyke KE, Kitchin N, Absalon J, Gurtman A, Lockhart S, et al. Phase I/II study of COVID-19 RNA vaccine BNT162b1 in adults. Nature. 2020;586:589-93.

23. Wang P, Casner RG, Nair MS, Wang M, Yu J, Cerutti G, et al. Increased resistance of SARS-CoV-2 variant P.1 to antibody neutralization. Cell Host Microbe. 2021;29:747-51.

24. Bird S, Panopoulou A, Shea RL, Tsui M, Saso R, Sud A, et al. Response to first vaccination against SARS-CoV-2 in patients with multiple myeloma. Lancet Haematol. 2021;8:e389-e392.
25. Krammer F, Srivastava K, Alshammary H, Amoako AA, Awawda MH, Beach FK, et al. Antibody responses in seropositive persons after a single dose of SARS-CoV2 mRNA vaccine. N Engl J Med. 2021;384:1372-74.

26. Salazar E, Kuchipudi SV, Christensen PA, Eagar T, Yi X, Zhao P, et al. Convalescent plasma anti-SARS-CoV-2 spike protein ectodomain and receptor-binding domain IgG correlate with virus neutralization. J Clin Investig. 2020;130:6728-38.

\section{ACKNOWLEDGEMENTS}

This publication was supported by the National Institute of Allergy and Infectious Diseases under award T32A1074492 and Institute for Myeloma and Bone Cancer Research.

\section{AUTHOR CONTRIBUTIONS}

SDS and JRB conceived and designed the project. SDS designed the spike ELISA assay which was optimized chiefly by M-SG but also by HC, ML, and NX. Author M-SG ran the COVID-19 ELISAs. AJF collected the swab and clinical history on the patient who developed a breakthrough COVID-19 infection. BR, DD, HC, NX, ML, TG, EF, and EA collected and organized patient data and sera included here. SDS, MG, JRB, BR, SJ, and SB analyzed the raw data. SJ and SB did the statistical analyses on the data, which were reviewed and edited by KP. Authors SDS, JRB, SJ, SB, and TMS wrote the paper. The underlying data was reviewed and verified by SDS, MG, SJ, and SB.

\section{COMPETING INTERESTS}

The authors declare no competing interests.

\section{ADDITIONAL INFORMATION}

Supplementary information The online version contains supplementary material available at https://doi.org/10.1038/s41375-021-01354-7.

Correspondence and requests for materials should be addressed to J.R.B.

Reprints and permission information is available at http://www.nature.com/ reprints

Publisher's note Springer Nature remains neutral with regard to jurisdictional claims in published maps and institutional affiliations. 